\title{
Heart disease among adults exposed to the September 11, 2001 World Trade Center disaster: Results from the World Trade Center Health Registry
}

\author{
Hannah T. Jordan a,*, Sara A. Miller-Archie a , James E. Cone a , Alfredo Morabia ${ }^{\text {b,c }}$, Steven D. Stellman a,b \\ ${ }^{a}$ World Trade Center Health Registry, New York City Department of Health and Mental Hygiene, 42-09 28th Street, Long Island City, NY 11101, USA \\ ${ }^{\mathrm{b}}$ Department of Epidemiology, Mailman School of Public Health, Columbia University, 722 West 168th Street, New York, NY 10032, USA \\ c Center for the Biology of Natural Sciences, Department of Earth and Environmental Sciences, City University of New York, 356 Fifth Avenue, Room 4306, New York, NY 10016, USA
}

\section{A R T I C L E I N F O}

Available online 28 October 2011

\section{Keywords:}

Cardiovascular disease

Heart disease

World Trade Center

Disaster registry

Cohort

Internal comparisons

Proportional hazards

Rescue/recovery workers

Occupational exposures

\section{A B S T R A C T}

Objective. To examine associations between 9/11-related exposures, posttraumatic stress disorder (PTSD), and subsequent development of heart disease (HD).

Methods. We prospectively followed 39,324 WTC Health Registry participants aged $\geq 18$ on $9 / 11$ for an average of 2.9 years. HD was defined as self-reported physician-diagnosed angina, heart attack, and/or other HD reported between study enrollment (2003-2004) and a follow-up survey (2006-2008) in enrollees without previous HD. A PTSD Checklist (PCL) score $\geq 44$ was considered PTSD. We calculated adjusted hazard ratios (AHR) and 95\% confidence intervals $(\mathrm{CI})$ to examine relationships between 9/11-related exposures and HD.

Results. We identified 1162 HD cases (381 women, 781 men). In women, intense dust cloud exposure was significantly associated with HD (AHR $1.28,95 \%$ CI 1.02-1.61). Injury on 9/11 was significantly associated with HD in women (AHR 1.46, 95\% CI 1.19-1.79) and in men (AHR 1.33, 95\% CI 1.15-1.53). Participants with PTSD at enrollment had an elevated HD risk (AHR 1.68, 95\% CI 1.33-2.12 in women, AHR 1.62, 95\% CI 1.34-1.96 in men). A dose-response relationship was observed between PCL score and HD risk.

Conclusion. This exploratory study suggests that exposure to the WTC dust cloud, injury on 9/11 and 9/ 11-related PTSD may be risk factors for HD.

(c) 2011 Elsevier Inc. All rights reserved.

\section{Introduction}

During the September 11, 2001 World Trade Center (WTC) terrorist attack, many survivors experienced exposures that could potentially have raised their risk for heart disease (HD). The concentration of airborne particulate matter (PM), which has been linked to increased cardiovascular disease (CVD) morbidity and mortality in other settings (Brook et al., 2010), was extremely high in the dust cloud resulting from the collapse of the WTC towers, and remained elevated in lower Manhattan for weeks thereafter (Thurston et al., 2003). Previous studies have evaluated short-term changes in cardiovascular outcomes after acute elevations in PM concentration, or examined associations between sustained PM exposure and long-term CVD

Abbreviations: AHR, adjusted hazard ratio; CDC, Centers for Disease Control and Prevention; CVD, cardiovascular disease; DOHMH, Department of Health and Mental Hygiene; HD, heart disease; NYC, New York City; PCL, PTSD checklist; PM, particulate matter; PTSD, posttraumatic stress disorder; WTC, World Trade Center; WTCHR, World Trade Center Health Registry; W1, Wave 1; W2, Wave 2.

* Corresponding author at: World Trade Center Health Registry, New York City Department of Health and Mental Hygiene, 42-09 28th Street, WS 7-32, Long Island City, NY 11101, USA. Fax: +1 3473962893.

E-mail address: hjordan1@health.nyc.gov (H.T. Jordan). risk (Brook et al., 2010). Whether intense but circumscribed PM exposure such as that resulting from the $9 / 11$ dust cloud also increases long-term HD risk is relatively unexplored.

In addition to inhaled pollutants, 9/11 survivors were exposed to severe psychological stress. Psychological stress resulting from disasters, as well as from daily emotional strain, has been linked to both acute and long-term increases in CVD risk (Armenian et al., 1998; Gullette et al., 1997; Jiang et al., 1996; Nakagawa et al., 2009; Stalnikowicz and Tsafrir, 2002). An association has also been identified between HD mortality and one outcome of severe psychological stress, posttraumatic stress disorder (PTSD), among combat veterans (Ahmadi et al., 2011; Boscarino, 2008; Kubzansky et al., 2007). Because PTSD is one of the most common 9/11-related health problems reported to date (Brackbill et al., 2009; Stellman et al., 2008), it may have contributed substantially to increased HD risk in heavily exposed populations.

Elevations in HD-related hospitalizations were observed in lower Manhattan and neighboring areas within the 2 months following 9/11 (Allegra et al., 2005; Feng et al., 2006; Lin et al., 2010), although cardiac mortality among New York City (NYC) residents was not increased during the month after 9/11 (Chi et al., 2003). These investigations were ecological in nature, limiting inferences about 9/11 exposure and HD risk. A study of cardiac function among police 
officers 7-8 years after 9/11 found increased left ventricular dysfunction as well as isolated right ventricular diastolic dysfunction (Croft et al., 2010). In a previous WTCHR study, high levels of exposure were associated with heart disease-related mortality among non-rescue/ recovery enrollees [adjusted hazard ratio (AHR) 2.06, 95\% CI 1.103.86] (Jordan et al., 2011).

We hypothesized that there was a sustained increase in HD risk among 9/11 survivors who were directly exposed to WTC dust and/ or psychological stress. We studied non-fatal HD among enrollees in the WTC Health Registry (the Registry), a volunteer registry that prospectively monitors the health of persons exposed to the 9/11 disaster. We sought to determine whether HD was associated with 9/11related exposures.

\section{Methods}

\section{Study population}

The Registry's methods were described previously (Farfel et al., 2008). Briefly, potential enrollees were rescue/recovery workers and volunteers; lower Manhattan area residents, workers, school staff and attendees; and commuters and passersby on 9/11. Lists of potentially eligible persons were obtained from lower Manhattan area employers and government agencies (list-identified enrollees), and multilingual media campaigns were used to encourage other potentially eligible persons (self-identified enrollees) to enroll via a website or toll-free telephone number. Between September 2003 and November 2004, 71,434 eligible persons provided verbal informed consent and completed a Wave 1 (W1) computer-assisted (95\%) or in-person (5\%) enrollment interview on demographics, 9/11-related exposures, and health information. Between November 2006 and January 2008, 46,602 enrollees updated their health information and clarified their $9 / 11$ exposures on a Wave 2 (W2) questionnaire via mail (46\%), website (42\%), or telephone (12\%). The Registry protocol was approved by the Centers for Disease Control and Prevention (CDC) and NYC Department of Health and Mental Hygiene (DOHMH) institutional review boards.

\section{Study outcome}

HD was defined as self-reported angina, heart attack, or any other heart condition first diagnosed by a physician between Registry enrollment and the W2 survey. We refer to self-reported, physician-diagnosed HD as HD for the remainder of this manuscript. Because the W2 survey only asked for a year of diagnosis, we assigned a diagnosis date of June 30 of the reported year. For enrollees who reported being diagnosed the same year they completed W1, we assigned a W1 survey date of June 30 of that year and a diagnosis date of December 31 of the same year. For those diagnosed in 2003, we assigned a W1 survey date of September 5, as that was the date the survey officially launched. Person-years were counted from the date of enrollment.

\section{Additional study variables}

We categorized enrollees into mutually exclusive, hierarchical eligibility groups based on likelihood of exposure, with rescue/recovery enrollees followed by lower Manhattan residents, lower Manhattan area workers, and passersby on September 11. Data on socio-demographic factors, smoking, and physician-diagnosed hypertension and diabetes were obtained from the W1 questionnaire. Some dust cloud exposure was defined as being caught in the dust cloud on the morning of 9/11 and reporting a geocodable location in lower Manhattan; intense exposure was being caught in the dust cloud on the morning of 9/11 and answering any of the following questions affirmatively: could not see a couple of feet in front of me; had trouble walking or finding my way because the dust was so thick; had to find shelter such as under a car or in a doorway; was covered from head to toe with dust or debris; or could not hear anything (Brackbill et al., 2009). Because injury on 9/11 was associated with both asthma and PTSD in previous studies (Brackbill et al., 2009; Galea et al., 2003), it is thought to be a marker for higher levels of dust cloud and psychological exposures; we therefore explored 9/11-related injury as a potential HD risk factor. Injury was defined as reporting any of the following on 9/11: cut, abrasion, or puncture wound; eye injury or irritation; sprain or strain; burn; broken or dislocated bone; and concussion or head injury.
For rescue/recovery workers, initiation of work was categorized as $9 / 11$ plus work on the dust/debris pile; $9 / 11$ but no pile work; $9 / 12-9 / 17$; or $9 /$ 18-June 2002. Lower Manhattan area residents and workers were asked about the degree of damage to their home or workplace; these measures were categorized as no damage, damage without a heavy layer of dust, or a heavy layer of dust with or without damage.

Posttraumatic stress symptoms were assessed with the PTSD Checklist ( $\mathrm{PCL})$, a validated, 17-item, event-specific scale that inquired about symptoms within the 30 preceding days (Blanchard et al., 1996; Ventureyra et al., 2002; Weathers et al., 1993). Question scores ranged from 1 (no symptoms) to 5 (severe), such that total scores ranged from 17 to 85 . Responses missing answers to any of the 17 questions were considered invalid. Probable PTSD (referred to as PTSD hereafter) was defined as a score $\geq 44$ (Blanchard et al., 1996).

We used quartiles of the total PCL score but additionally subdivided the upper quartile into three levels in order to distinguish the two commonly used cutoff points for defining PTSD, 44 and 50 (Stellman et al., 2008). The resulting PCL score categories were: $17-19$ (20.9\% of participants); $20-25$ (28.6\%); 26-34 (23.7\%); 35-43 (13.3\%); 44-49 (5.1\%); and $\geq 50$ (8.4\%).

\section{Inclusion and exclusion criteria}

Enrollees aged $\geq 18$ years on $9 / 11$ who completed $W 2(n=46,012)$ were eligible. We excluded enrollees who were lower Manhattan area school students or staff but did not belong to other eligibility groups due to small numbers $(n=56)$, those with HD before study enrollment $(n=4719)$, and those missing data on HD history or year of diagnosis $(n=1913)$.

\section{Statistical analyses}

Person-time began on the date of Registry enrollment and ended at the HD diagnosis date or the W2 survey completion date, whichever was earlier. We stratified analyses on sex given well-established differences between HD risk profiles for men and women. Proportional hazards regression models adjusted for age, race/ethnicity, education, marital status, smoking, history of hypertension, and history of diabetes were used to estimate hazard ratios (HR) and 95\% confidence intervals (CI) for HD. We evaluated the impact of adjustment for Registry eligibility group in models including the complete study sample, but no substantial changes in the HRs were observed, so eligibility group was not included in final models. We added PTSD to models with 9/11-related exposure variables to evaluate whether PTSD and 9/11-related exposures were independently associated with HD. There was no evidence that the data violated the proportional hazards assumption. Analyses used SAS version 9.2 (SAS Institute Inc., Cary, North Carolina).

\section{Results}

Table 1 shows socio-demographic characteristics, 9/11-related exposures, and physical and mental health conditions present upon enrollment for the 39,324 study participants, who were followed for an average of 2.9 years. Participants were primarily white, aged 25-44 at 9/11, and highly educated. The mean age was 43.9 years [standard deviation $(\mathrm{SD})=11.8$ ] for women and 44.0 years $(S D=10.4)$ for men. Nearly one-third $(29.9 \%$ of women and $29.4 \%$ of men) reported being heavily exposed to the $9 / 11$ dust cloud. Incurring one or more injuries on $9 / 11$ was reported by $36.6 \%$ of women and $38.7 \%$ of men. At study enrollment (2003-2004), 16.6\% of women and $10.9 \%$ of men screened positive for PTSD. Enrollees who did not participate in W2 $(n=20,164)$ were similar to those who did complete W2 in terms of a history of smoking, hypertension, and diabetes. However, non-participants had higher rates of probable PTSD at W1 (women: 21.5\%; men: $15.7 \%$ ), and were more likely to have been non-Hispanic black, Hispanic or Asian and to be list-identified.

On the W2 survey, 1162 enrollees reported being diagnosed with HD since enrollment. Of these, 125 (10.8\%) reported being diagnosed with angina, 140 (12.0\%) with a heart attack, 746 (64.2\%) with other heart disease, and 151 (13.0\%) with more than one of these diagnoses. The HD incidence rate was $859.1 / 100,000$ person-years in women and 1130.4/100,000 person-years in men. 
Table 1

Characteristics of the study population. World Trade Center Health Registry participants aged $\geq 18$ on September 11, 2011, New York, 2003-2008.

\begin{tabular}{|c|c|c|c|c|}
\hline \multirow[t]{3}{*}{ Characteristic } & \multicolumn{2}{|c|}{ W2 participants } & \multicolumn{2}{|c|}{ W2 non-participants } \\
\hline & \multirow{2}{*}{$\begin{array}{l}\text { Women } \\
\mathrm{n}=15,102 \\
\end{array}$} & \multirow{2}{*}{$\begin{array}{l}\text { Men } \\
\mathrm{n}=24,222 \\
\%\end{array}$} & \multirow{2}{*}{$\begin{array}{l}\text { Women } \\
\mathrm{n}=8160 \\
\%\end{array}$} & \multirow{2}{*}{$\begin{array}{l}\text { Men } \\
\mathrm{n}=12,004 \\
\%\end{array}$} \\
\hline & & & & \\
\hline \multicolumn{5}{|l|}{ Age at enrollment (years) } \\
\hline $18-24$ & 3.9 & 1.6 & 5.8 & 3.5 \\
\hline $25-44$ & 48.2 & 52.2 & 52.8 & 59.0 \\
\hline $45-64$ & 43.8 & 43.0 & 35.4 & 34.1 \\
\hline $65+$ & 4.0 & 3.2 & 6.1 & 3.4 \\
\hline \multicolumn{5}{|l|}{ Race/ethnicity } \\
\hline Non-Hispanic white & 62.1 & 76.5 & 42.8 & 57.9 \\
\hline Non-Hispanic black & 15.5 & 6.4 & 21.1 & 12.4 \\
\hline Hispanic & 12.4 & 10.0 & 17.8 & 15.8 \\
\hline Asian & 6.3 & 4.4 & 12.2 & 8.4 \\
\hline Other & 3.8 & 2.7 & 6.2 & 5.6 \\
\hline \multicolumn{5}{|l|}{ Education } \\
\hline Less than high school & 2.2 & 3.2 & 7.4 & 7.9 \\
\hline High school & 14.9 & 19.4 & 17.7 & 22.7 \\
\hline Some college & 22.3 & 25.9 & 23.8 & 23.6 \\
\hline College graduate & 59.9 & 50.8 & 47.9 & 42.8 \\
\hline \multicolumn{5}{|l|}{ Employment status } \\
\hline Full/self employed & 84.1 & 88.9 & 76.4 & 83.6 \\
\hline Unemployed & 15.6 & 10.7 & 21.1 & 13.7 \\
\hline \multicolumn{5}{|l|}{ Marital Status } \\
\hline Married & 43.0 & 69.7 & 38.8 & 58.0 \\
\hline Widowed/divorced/separated & 18.9 & 8.3 & 20.6 & 10.7 \\
\hline Never married & 29.2 & 15.6 & 29.7 & 20.8 \\
\hline Living with partner & 8.0 & 5.9 & 7.2 & 7.4 \\
\hline \multicolumn{5}{|l|}{ Eligibility group ${ }^{\mathrm{a}}$} \\
\hline Rescue/recovery worker & 26.6 & 60.6 & 24.1 & 53.1 \\
\hline $\begin{array}{l}\text { Lower Manhattan area } \\
\text { resident }\end{array}$ & 20.6 & 9.3 & 26.3 & 14.6 \\
\hline Lower Manhattan area worker & 46.3 & 26.9 & 42.4 & 28.1 \\
\hline Passerby/commuter on $9 / 11$ & 6.5 & 3.2 & 7.2 & 4.3 \\
\hline \multicolumn{5}{|l|}{ Study recruitment source } \\
\hline List & 22.7 & 28.6 & 32.4 & 43.7 \\
\hline Self & 77.3 & 71.4 & 67.6 & 56.3 \\
\hline \multicolumn{5}{|l|}{ Smoking status } \\
\hline Never & 58.2 & 55.8 & 61.8 & 54.5 \\
\hline Current & 14.6 & 15.1 & 16.3 & 20.0 \\
\hline Former & 26.6 & 28.6 & 19.5 & 23.0 \\
\hline \multicolumn{5}{|c|}{ History of hypertension at enrollment } \\
\hline Yes & 13.9 & 16.1 & 15.1 & 15.2 \\
\hline No & 85.9 & 83.7 & 84.2 & 83.9 \\
\hline \multicolumn{5}{|c|}{ History of diabetes at enrollment } \\
\hline Yes & 3.4 & 3.8 & 4.5 & 4.4 \\
\hline No & 96.4 & 96.0 & 94.9 & 94.9 \\
\hline \multicolumn{5}{|l|}{ 9/11 dust cloud exposure ${ }^{b}$} \\
\hline Intense & 29.9 & 29.4 & $\mathrm{n} / \mathrm{a}$ & $\mathrm{n} / \mathrm{a}$ \\
\hline Some & 16.3 & 12.2 & $\mathrm{n} / \mathrm{a}$ & $\mathrm{n} / \mathrm{a}$ \\
\hline None & 50.6 & 54.5 & $\mathrm{n} / \mathrm{a}$ & $\mathrm{n} / \mathrm{a}$ \\
\hline \multicolumn{5}{|l|}{ Injured on $9 / 11^{c}$} \\
\hline Yes & 36.6 & 38.7 & 37.8 & 37.2 \\
\hline No & 63.4 & 61.3 & 62.2 & 62.8 \\
\hline PTSD at enrollment ${ }^{\mathrm{d}}$ & & & & \\
\hline Yes & 16.6 & 10.9 & 21.5 & 15.7 \\
\hline No & 80.6 & 87.0 & 71.5 & 79.0 \\
\hline
\end{tabular}

Rescue/recovery workers/volunteers

\begin{tabular}{|c|c|c|c|c|}
\hline & $\mathrm{n}=4018$ & $\mathrm{n}=14,675$ & $\mathrm{n}=1967$ & $\mathrm{n}=6370$ \\
\hline \multicolumn{5}{|l|}{ Time of arrival } \\
\hline $9 / 11$, on pile & 2.5 & 18.8 & 2.0 & 13.2 \\
\hline 9/11, other WTC site & 11.2 & 14.0 & 10.8 & 14.0 \\
\hline $9 / 12-9 / 17$ & 29.6 & 42.0 & 31.4 & 43.6 \\
\hline $9 / 18-6 / 2002$ & 52.2 & 21.9 & 50.6 & 26.2 \\
\hline \multicolumn{5}{|l|}{ Lower Manhattan area residents } \\
\hline & $\mathrm{n}=3104$ & $\mathrm{n}=2260$ & & \\
\hline \multicolumn{5}{|l|}{ Damage to home ${ }^{b}$} \\
\hline Heavy layer of dust \pm damage & 16.7 & 17.0 & $\mathrm{n} / \mathrm{a}$ & $\mathrm{n} / \mathrm{a}$ \\
\hline $\begin{array}{l}\text { Damage without heavy layer of } \\
\text { dust }\end{array}$ & 12.9 & 12.0 & $\mathrm{n} / \mathrm{a}$ & $\mathrm{n} / \mathrm{a}$ \\
\hline No damage & 70.3 & 70.9 & $\mathrm{n} / \mathrm{a}$ & $\mathrm{n} / \mathrm{a}$ \\
\hline
\end{tabular}

Table 1 (continued)

\begin{tabular}{lclll}
\hline Lower Manhattan area workers & & & \\
\hline & $\mathrm{n}=6995$ & $\mathrm{n}=6505$ & & \\
\hline Damage to workplace $^{\mathrm{b}}$ & & & & \\
$\quad$ Heavy layer of dust \pm damage & 8.9 & 11.2 & $\mathrm{n} / \mathrm{a}$ & $\mathrm{n} / \mathrm{a}$ \\
Damage without heavy layer of dust & 15.2 & 14.9 & $\mathrm{n} / \mathrm{a}$ & $\mathrm{n} / \mathrm{a}$ \\
No damage & 75.8 & 73.9 & $\mathrm{n} / \mathrm{a}$ & $\mathrm{n} / \mathrm{a}$
\end{tabular}

Abbreviations: posttraumatic stress disorder (PTSD).

Percents may not sum to 100 due to missing values.

a Enrollees were categorized into mutually exclusive, hierarchical eligibility groups based on likelihood of degree of exposure, with rescue/recovery enrollees followed by lower Manhattan residents, lower Manhattan area workers, and passersby on September 11.

b Variables required both Wave 1 and Wave 2 data.

c Injury was defined as any of the following on 9/11: cut, abrasion, or puncture wound; eye injury or irritation; sprain or strain; burn; broken or dislocated bone; concussion or head injury.

d PTSD was defined as a PCL score $\geq 44$.

Table 2 shows associations between HD and socio-demographic factors and previous medical history. Smoking was positively associated with HD risk among men but not women. Among both sexes, a history of hypertension or diabetes was associated with an elevated HD risk.

\section{9/11 dust exposure and heart disease}

We examined relationships between 9/11-related dust exposures, including several specific to individual Registry eligibility groups, and HD in multivariable models (Table 3). Accounting for other factors, intense dust cloud exposure was associated with HD among women (AHR 1.28, 95\% CI 1.02-1.61), but the association did not reach statistical significance among men (AHR 1.14, 95\% CI 0.97-1.34). Male rescue/recovery workers who worked on the pile on $9 / 11$ had a higher HD risk compared to those who arrived on 9/18 or later (AHR 1.39, 95\% CI 1.04-1.86). Among female rescue/recovery workers, the association between working on the pile on 9/11 and HD was not statistically significant, although working on another WTC site on 9/11 and arrival between 9/12 and 9/17 were each significantly associated with an elevated HD risk (AHR 1.94, 95\% CI 1.10-3.42 and AHR 1.76, $95 \%$ CI 1.11-2.77, respectively). The association between heavy dust in the home and HD was significant among male but not female lower Manhattan area residents (AHR 2.05, 95\% CI 1.15-3.67, AHR 1.23, 95\% CI 0.63-2.42, respectively). Similarly, encountering a heavy layer of dust upon return to a lower Manhattan area workplace was associated with an elevated HD risk among men but not women (AHR 1.55, 95\% CI 1.03-2.31, AHR 1.35, 95\% CI 0.852.14, respectively).

\section{Injury, psychological stress, and heart disease}

We evaluated associations between injury on 9/11, psychological stress (PTSD as measured by the 9/11-specific PCL score), and subsequent HD. Table 4 shows adjusted hazard ratios for HD in relation to 9/11 dust cloud exposure, injury, and PTSD separately (Models 1, 2, and 3, respectively). Injury on 9/11 and PTSD at enrollment were both significantly associated with subsequent $\mathrm{HD}$ in men and women, with hazard ratios ranging from 1.33 to 1.68 . Whereas intense dust cloud exposure by itself was a significant predictor of HD in women (Model 1: AHR 1.28, 95\%CI 1.02-1.61) and nearly so in men (AHR 1.14, 95\% CI 0.97-1.34), it was attenuated when PTSD was also included (Model 4) and not significant in either sex. However, injury and PTSD considered jointly (Model 5) were significant predictors of HD in both women and men, suggesting that they may be independent risk factors for HD. In these models, PTSD at 
Table 2

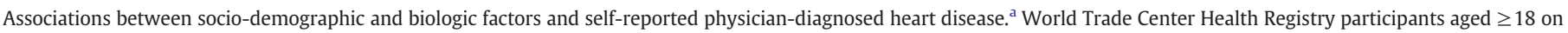
September 11, 2001 ( $n=39,324)$, New York, 2003-2008.

\begin{tabular}{|c|c|c|c|c|c|c|c|c|}
\hline & \multicolumn{4}{|l|}{ Women } & \multicolumn{4}{|l|}{ Men } \\
\hline & No. with $\mathrm{HD}^{\mathrm{b}}$ & Person-time (years) & $\mathrm{AHR}^{\mathrm{C}}$ & $95 \% \mathrm{CI}$ & No. with $\mathrm{HD}^{\mathrm{b}}$ & Person-time (years) & $\mathrm{AHR}^{\mathrm{c}}$ & $95 \% \mathrm{CI}$ \\
\hline Age on 9/11 (years) & & & 1.03 & $1.02-1.04$ & & & 1.05 & $1.04-1.05$ \\
\hline \multicolumn{9}{|l|}{ Race/ethnicity } \\
\hline Non-Hispanic white & 204 & 27,496 & Ref & & 561 & 52,745 & Ref & \\
\hline Non-Hispanic black & 82 & 6862 & 1.30 & $0.99-1.71$ & 51 & 4544 & 0.92 & $0.69-1.24$ \\
\hline Hispanic & 61 & 5451 & 1.39 & $1.03-1.88$ & 95 & 6853 & 1.32 & $1.05-1.65$ \\
\hline Asian & 16 & 2734 & 0.71 & $0.42-1.21$ & 41 & 3065 & 1.20 & $0.87-1.66$ \\
\hline Other & 18 & 1685 & 1.20 & $0.71-2.02$ & 33 & 1874 & 1.62 & $1.13-2.33$ \\
\hline \multicolumn{9}{|l|}{ Education } \\
\hline Less than high school & 15 & 966 & 1.39 & $0.80-2.44$ & 47 & 2227 & 1.41 & $1.02-1.93$ \\
\hline High school & 78 & 6601 & 1.27 & $0.96-1.68$ & 164 & 13,364 & 1.12 & $0.93-1.36$ \\
\hline Some college & 114 & 9852 & 1.46 & $1.14-1.87$ & 224 & 17,767 & 1.30 & $1.09-1.54$ \\
\hline College graduate & 167 & 26,538 & Ref & & 342 & 35,324 & Ref & \\
\hline \multicolumn{9}{|l|}{ Marital status } \\
\hline Married & 152 & 19,101 & Ref & & 582 & 47,944 & Ref & \\
\hline Widowed/divorced/separated & 125 & 8277 & 1.32 & $1.03-1.70$ & 98 & 5724 & 1.17 & $0.94-1.46$ \\
\hline Never married & 68 & 12,948 & 0.81 & $0.60-1.08$ & 62 & 10,983 & 0.67 & $0.51-0.87$ \\
\hline Living with partner & 30 & 3516 & 1.28 & $0.86-1.90$ & 36 & 4087 & 0.86 & $0.61-1.21$ \\
\hline \multicolumn{9}{|l|}{ Smoking status } \\
\hline Never & 220 & 25,708 & Ref & & 354 & 38,502 & Ref & \\
\hline Current & 52 & 6458 & 0.91 & $0.67-1.24$ & 160 & 10,468 & 1.65 & $1.36-2.00$ \\
\hline Former & 106 & 11,822 & 0.90 & $0.71-1.15$ & 262 & 19,751 & 1.06 & $0.90-1.25$ \\
\hline \multicolumn{9}{|c|}{ History of hypertension at enrollment } \\
\hline Yes & 109 & 6085 & 1.56 & $1.22-1.99$ & 203 & 11,006 & 1.28 & $1.08-1.52$ \\
\hline No & 268 & 38,053 & Ref & & 573 & 57,935 & Ref & \\
\hline \multicolumn{9}{|l|}{ History of diabetes at enrollment } \\
\hline Yes & 31 & 1500 & 1.54 & $1.05-2.25$ & 72 & 2614 & 1.51 & $1.17-1.94$ \\
\hline No & 348 & 42,650 & Ref & & 708 & 66,378 & Ref & \\
\hline
\end{tabular}

Abbreviations: Heart disease (HD); adjusted hazard ratio (AHR); confidence interval (CI).

a Heart disease defined as physician-diagnosed angina, heart attack, or other heart problem first reported on the 2006-2008 Wave 2 survey.

b Frequencies may not sum to total due to missing values.

c Hazard ratio adjusted for all other variables in the table.

enrollment was represented as a binary (yes/no) variable based on the commonly used cutoff score of 44 .

Fig. 1 shows the relationship between PTSD and HD with an alternative representation of PTSD that uses a six-category grouping of PCL scores. In this model, the AHR increases monotonically with the PCL score and is significantly above 1.0 for scores as low as 26-34.

\section{Sensitivity analysis of primary outcome}

Using an alternate definition of HD restricted to incident angina and/or heart attack, we found similar associations with both 9/11related exposures and PTSD (data not shown).

\section{Discussion}

The WTC disaster produced a unique combination of physical and psychological exposures that may have impacted survivors' risk for chronic HD. In this exploratory study, we investigated relationships between exposure to air pollution and psychological stress on 9/11 and new-onset HD. We found that, two to six years following the disaster, measures of dust cloud exposure, injury and PTSD were each associated with an elevated risk of non-fatal self-reported physician-diagnosed HD. With a few exceptions, findings were similar among men and women.

Prospective studies of US veterans have found that PTSD is independently associated with both coronary atherosclerosis and an elevated risk of all-cause and HD-related mortality (Ahmadi et al.,
2011; Boscarino, 2008; Kubzansky et al., 2007). Our results add to the more limited body of work on PTSD and HD risk among civilian populations. Although the exact mechanisms for the association between PTSD and HD remain undefined, it has been proposed that psychological stress may accelerate atherosclerosis via excess sympathetic nervous system activation (Rozanski et al., 1999). PTSD may also contribute to HD risk though the disorder's association with health behaviors that are known cardiovascular risk factors, including smoking (Beckham et al., 1997; Breslau et al., 2003).

We found that HD risk increased steadily with PCL score. This is consistent with the observation of a dose-response relationship between the level of PTSD symptoms and the risk of medically confirmed coronary HD in a prospective study of US military veterans (Kubzansky et al., 2007). In keeping with a growing body of evidence that "subthreshold" posttraumatic stress symptoms can result in deleterious effects on general functional status (Grubaugh et al., 2005; Jakupcak et al., 2011; Marshall et al., 2001), we also found that a significant association between posttraumatic stress symptoms and HD risk was present at PCL scores substantially below the commonly used PCL score cutoff of 44 . These results suggest that further investigation of the relationship between PTSD and HD should consider subthreshold symptoms as a potential risk factor. PTSD attenuates the association between dust cloud and HD in women, suggesting that PTSD could be explored as a mediator of exposures experienced on 9/11 in future studies.

Our results must be interpreted with caution. Our HD definition was a composite of angina, heart attack, and/or other HD (constituting the majority of cases), so the exact nature of the reported heart 
Table 3

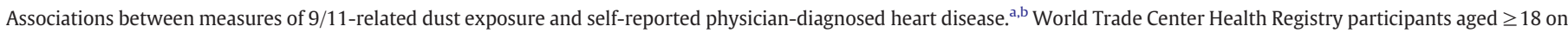
September 11, 2011 ( $n=39,324)$, New York, 2003-2008.

\begin{tabular}{|c|c|c|c|c|c|c|c|c|}
\hline \multirow[b]{2}{*}{ Exposure } & \multicolumn{4}{|l|}{ Women } & \multicolumn{4}{|l|}{ Men } \\
\hline & No. with $\mathrm{HD}^{\mathrm{c}}$ & Person-time (years) & AHR & $95 \% \mathrm{CI}$ & No. with $\mathrm{HD}^{\mathrm{c}}$ & Person-time (years) & AHR & $95 \% \mathrm{CI}$ \\
\hline \multicolumn{9}{|l|}{ All enrollees } \\
\hline \multicolumn{9}{|l|}{ 9/11 dust cloud exposure } \\
\hline Intense & 141 & 13,357 & 1.28 & $1.02-1.61$ & 243 & 20,371 & 1.14 & $0.97-1.34$ \\
\hline Some & 48 & 7247 & 0.83 & $0.60-1.14$ & 90 & 8500 & 1.00 & $0.79-1.25$ \\
\hline None & 171 & 22,237 & Ref & & 412 & 37,511 & Ref & \\
\hline \multicolumn{9}{|l|}{ Rescue/recovery workers } \\
\hline \multicolumn{9}{|l|}{ Time of arrival } \\
\hline 9/11, on pile & 4 & 292 & 2.25 & $0.79-6.40$ & 87 & 7452 & 1.39 & $1.04-1.86$ \\
\hline 911, other WTC site & 19 & 1298 & 1.94 & $1.10-3.42$ & 71 & 5846 & 1.21 & $0.89-1.63$ \\
\hline $9 / 12-9 / 17$ & 39 & 3404 & 1.76 & $1.11-2.77$ & 216 & 17,420 & 1.24 & $0.98-1.56$ \\
\hline $9 / 18-6 / 2002$ & 44 & 6186 & Ref & & 112 & 9293 & Ref & \\
\hline \multicolumn{9}{|l|}{ Area residents } \\
\hline \multicolumn{9}{|l|}{ Damage to home } \\
\hline Heavy layer of dust \pm damage & 12 & 1543 & 1.23 & $0.63-2.42$ & 18 & 1152 & 2.05 & $1.15-3.67$ \\
\hline Damage without heavy layer of dust & 13 & 1213 & 1.69 & $0.87-3.25$ & 7 & 841 & 1.09 & $0.48-2.48$ \\
\hline None & 34 & 6369 & Ref & & 39 & 4666 & Ref & \\
\hline \multicolumn{9}{|l|}{ Area workers } \\
\hline \multicolumn{9}{|l|}{ Damage to workplace } \\
\hline Heavy layer of dust \pm damage & 21 & 1822 & 1.35 & $0.85-2.14$ & 31 & 2075 & 1.55 & $1.03-2.31$ \\
\hline Damage without heavy layer of dust & 31 & 3178 & 1.23 & $0.83-1.82$ & 29 & 2864 & 1.12 & $0.75-1.69$ \\
\hline None & 128 & 15,501 & Ref & & 124 & 13,792 & Ref & \\
\hline
\end{tabular}

Abbreviations: Heart disease (HD); adjusted hazard ratio (AHR); confidence interval (CI).

a Heart disease defined as physician-diagnosed angina, heart attack, or other heart problem first reported on the 2006-2008 Wave 2 survey.

b Models were adjusted for age, race/ethnicity, education, marital status, smoking, hypertension, and diabetes.

c Frequencies may not sum to total due to missing values.

problems is unknown. We found similar associations between HD and both 9/11-related exposures and PTSD when we used an alternate definition of HD restricted to incident angina and/or heart attack. Nonetheless, clarification of the types of HD experienced by enrollees is needed. Because HD was self-reported, our findings require substantiation with more objectively defined end-points, such as medically confirmed HD. Previous studies of the validity of self-reported HD suggest that respondents tend to over-report individual HD events; however, when different cardiovascular events are combined into clinically relevant groups, such as the composite used in our study, self-report more closely matches medical records (Barr et al., 2009, Joshi and Turnbill, 2009).

We relied on self-reported 9/11-related exposures because objective measures of these exposures are not available for our cohort. We assumed that PTSD identified at the time of Registry enrollment resulted from 9/11 exposure. Although we could not definitively determine what proportion of PTSD cases were due to other traumatic experiences, results of the W2 survey indicate that only a small proportion of those screening positive for PTSD had also been diagnosed with PTSD before 9/11 (data not shown), suggesting that PTSD identified at W1 is likely to have been 9/11-related. A further limitation was our lack of information on important CVD risk factors, including dyslipidemia, family history, and depression. We may have had insufficient follow-up time to detect an association between smoking and HD among women, who tend to develop HD later in life compared to men. Additionally, our assignment of event dates was imprecise, and the relatively short duration of follow-up restricted our ability to perform detailed sub-group analyses.

Another important limitation is loss to follow-up between the W1 and W2 surveys. How this loss to follow-up may have impacted our results is unknown. However, W2 non-participants did not differ from participants regarding several key HD risk factors, including smoking, hypertension, and diabetes, suggesting that our results are likely to be representative of those for the full cohort.
Finally, because this study began two years after 9/11, we could not evaluate associations between 9/11 exposure and immediate HD risk. In-depth studies of HD among Registry enrollees and among members of other WTC cohorts will be needed to further elucidate the potential association between 9/11-related exposures and HD.

\section{Conclusion}

This study provided an opportunity to prospectively explore the relative importance of physical and psychological exposures for HD risk in a large and diverse cohort of $9 / 11$ survivors. With the exception of smoking among women, our results reflected established HD risk factors such as hypertension and diabetes, substantiating our findings on 9/11-related exposures. We found evidence that 9/11-related exposures were associated with an elevated HD risk several years after the disaster. These results have important implications for HD risk factor screening among persons who were directly exposed to the $9 / 11$ disaster, as they indicate that the intensity of dust exposure, injury incurred on 9/11, and the severity of PTSD should be considered in addition to the classic HD risk factors in this population.

\section{Funding}

This study was supported by Cooperative Agreement U50/ ATU272750 from the Agency for Toxic Substances and Disease Registry (ATSDR) of the Centers for Disease Control and Prevention (CDC), which included support from the National Center for Environmental Health (NCEH); Cooperative Agreement 1U50/OH009739 from the National Institute for Occupational Safety and Health (NIOSH); and the New York City Department of Health and Mental Hygiene (NYC DOHMH). ATSDR supported collection of survey data used in this analysis and participated in the overall design of the Registry. Neither NIOSH nor ATSDR had a role in the current study design, data 
Table 4

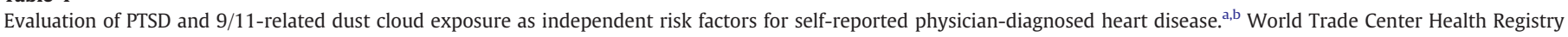
participants aged $\geq 18$ on September 11, 2001 ( $n=39,324)$, New York, 2003-2008.

\begin{tabular}{|c|c|c|c|c|c|c|c|c|}
\hline \multirow[b]{2}{*}{ Exposure(s) added to model } & \multicolumn{4}{|l|}{ Women } & \multicolumn{4}{|l|}{ Men } \\
\hline & No. with $\mathrm{HD}^{\mathrm{c}}$ & Person-time (years) & AHR & $95 \% \mathrm{CI}$ & No. with $\mathrm{HD}^{\mathrm{c}}$ & Person-time (years) & AHR & $95 \% \mathrm{CI}$ \\
\hline \multicolumn{9}{|l|}{ Model 1} \\
\hline \multicolumn{9}{|l|}{ 9/11 dust cloud exposure } \\
\hline Intense & 141 & 13,357 & 1.28 & $1.02-1.61$ & 243 & 20,371 & 1.14 & $0.97-1.34$ \\
\hline Some & 48 & 7247 & 0.83 & $0.60-1.14$ & 90 & 8500 & 1.00 & $0.79-1.25$ \\
\hline None & 171 & 22,237 & Ref & & 412 & 37,511 & Ref & \\
\hline \multicolumn{9}{|l|}{ Model 2} \\
\hline \multicolumn{9}{|l|}{ Injured on $9 / 11^{d}$} \\
\hline Yes & 186 & 16,298 & 1.46 & $1.19-1.79$ & 348 & 26,551 & 1.33 & $1.15-1.53$ \\
\hline No & 195 & 27,928 & Ref & & 433 & 42,529 & Ref & \\
\hline \multicolumn{9}{|l|}{ Model 3} \\
\hline \multicolumn{9}{|l|}{ PTSD at enrollment ${ }^{\mathrm{e}}$} \\
\hline Yes & 107 & 7317 & 1.68 & $1.33-2.12$ & 137 & 7491 & 1.62 & $1.34-1.96$ \\
\hline No & 260 & 35,688 & Ref & & 624 & 60,166 & Ref & \\
\hline \multicolumn{9}{|l|}{ Model 4} \\
\hline \multicolumn{9}{|l|}{ 9/11 dust cloud exposure } \\
\hline Intense & 136 & 13,002 & 1.17 & $0.92-1.48$ & 238 & 19,902 & 1.09 & $0.93-1.29$ \\
\hline Some & 47 & 7078 & 0.80 & $0.58-1.11$ & 89 & 8307 & 1.00 & $0.80-1.26$ \\
\hline None & 165 & 21,610 & Ref & & 400 & 36,816 & Ref & \\
\hline \multicolumn{9}{|l|}{ PTSD at enrollment ${ }^{\mathrm{e}}$} \\
\hline Yes & 101 & 7062 & 1.62 & $1.26-2.07$ & 126 & 7061 & 1.56 & $1.27-1.91$ \\
\hline No & 247 & 34,628 & Ref & & 601 & 57,965 & Ref & \\
\hline \multicolumn{9}{|l|}{ Model 5} \\
\hline \multicolumn{9}{|l|}{ Injured on $9 / 11^{d}$} \\
\hline Yes & 179 & 15,750 & 1.35 & $1.09-1.68$ & 344 & 25,964 & 1.29 & $1.12-1.50$ \\
\hline No & 188 & 27,253 & Ref & & 417 & 41,693 & Ref & \\
\hline \multicolumn{9}{|l|}{ PTSD at enrollment ${ }^{\mathrm{e}}$} \\
\hline Yes & 107 & 7317 & 1.54 & $1.21-1.97$ & 137 & 7491 & 1.50 & $1.24-1.83$ \\
\hline No & 260 & 35,686 & Ref & & 624 & 60,166 & Ref & \\
\hline
\end{tabular}

Abbreviations: Heart disease (HD); adjusted hazard ratio (AHR); confidence interval (CI); posttraumatic stress disorder (PTSD).

a HD was defined as physician-diagnosed angina, heart attack, or other heart problem first reported on the 2006-2008 Wave 2 survey.

b Models were also adjusted for age, race/ethnicity, education, marital status, smoking, hypertension, and diabetes.

c Frequencies may not sum to total due to missing values.

d Injury was defined as any of the following on 9/11: cut, abrasion, or puncture wound; eye injury or irritation; sprain or strain; burn; broken or dislocated bone; concussion or head injury.

e PTSD was defined as a PCL score $\geq 44$.

analysis, data interpretation, or writing of the report. NYC DOHMH participated in study design and development, data collection, and review of the manuscript.

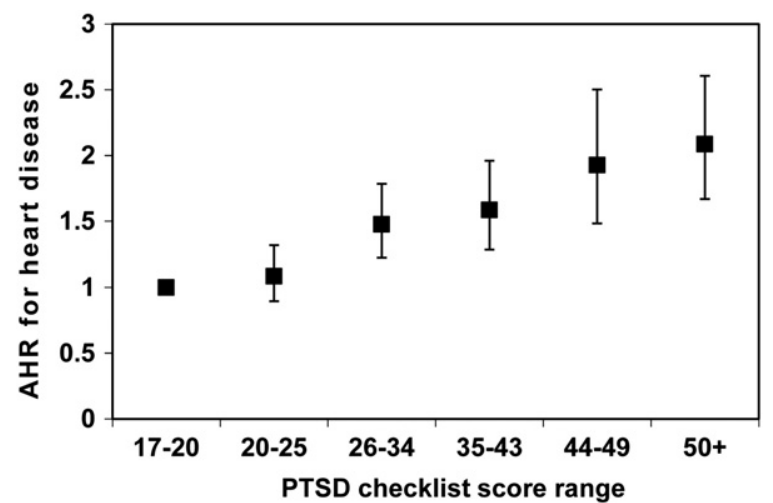

Fig. 1. Adjusted hazard ratios (AHR) for self-reported physician-diagnosed heart disease according to posttraumatic stress disorder (PTSD) checklist score for World Trade Center Health Registry participants aged $\geq 18$ on September 11, 2011 $(\mathrm{n}=39,324)$, New York, 2003-2008. Heart disease was defined as physician-diagnosed angina, heart attack, or other heart problem first reported on the 2006-2007 Wave 2 survey. Hazard ratios were adjusted for age, race/ethnicity, education, marital status, smoking, hypertension, and diabetes. Error bars represent 95\% confidence intervals.
Conflict of interest statement

The authors declare that there are no conflicts of interest.

\section{Acknowledgments}

We acknowledge Robert M. Brackbill, PhD, (World Trade Center Health Registry) for helping generate the hypotheses behind this study. We also acknowledge the invaluable contributions of Carolyn Greene, MD, James L. Hadler, MD, MPH, Jiehui Li, MBBS, MSc, Margaret Millstone, and Colleen Quinn.

\section{References}

Ahmadi, N., et al., 2011. Post-traumatic stress disorder, coronary atherosclerosis, and mortality. Am. J. Cardiol. 108, 29-33.

Allegra, J., et al., 2005. Cardiac events in New Jersey after the September 11, 2001, terrorist attack. J. Urban Health 82, 358-363.

Armenian, H.K., et al., 1998. Long term mortality and morbidity related to degree of damage following the 1988 earthquake in Armenia. Am. J. Epidemiol. 148, 1077-1084.

Barr, L.M., et al., 2009. Validity of self-reported cardiovascular disease events in comparison to medical record adjudication and a statewide hospital morbidity database: the AusDiab study. Intern. Med. J. 39, 49-53.

Beckham, J.C., et al., 1997. Prevalence and correlates of heavy smoking in Vietnam veterans with chronic posttraumatic stress disorder. Addict. Behav. 22, 637-647.

Blanchard, E.B., et al., 1996. Psychometric properties of the PTSD checklist (PCL). Behav. Res. Ther. 34, 669-673. 
Boscarino, J.A., 2008. A prospective study of PTSD and early-age heart disease mortality among Vietnam veterans: implications for surveillance and prevention. Psychosom. Med. 70, 668-676

Brackbill, R.M., et al., 2009. Asthma and posttraumatic stress symptoms 5 to 6 years following exposure to the World Trade Center terrorist attack. JAMA 302, 502-516.

Breslau, N., et al., 2003. Posttraumatic stress disorder and the incidence of nicotine, alcohol, and other drug disorders in persons who have experienced trauma. Arch. Gen. Psychiatry 60, 289-294.

Brook, R.D., et al., 2010. Particulate matter air pollution and cardiovascular disease: an update to the scientific statement from the American Heart Association. Circulation $121,2331-2378$.

Chi, J., et al., 2003. Cardiovascular mortality in New York City after September 11, 2001. Am. J. Cardiol. 92, 857-861.

Croft, L.B., et al., 2010. First documentation of cardiac dysfunction following exposure to the WTC disaster. A86.E810. J. Am. Coll. Cardiol. 55, 10A.

Farfel, M., et al., 2008. An overview of $9 / 11$ experiences and respiratory and mental health conditions among World Trade Center Health Registry enrollees. J. Urban Health 85, 880-909.

Feng, J., et al., 2006. Cardiac sequelae in Brooklyn after the September 11 terrorist attacks. Clin. Cardiol. 29, 13-17.

Galea, S., et al., 2003. Trends of probable post-traumatic stress disorder in New York City after the September 11 terrorist attacks. Am. J. Epidemiol. 158, 514-524.

Grubaugh, A.L., et al., 2005. Subthreshold PTSD in primary care: prevalence, psychiatric disorders, healthcare use, and functional status. J. Nerv. Ment. Dis. 193, 658-664.

Gullette, E.C.D., et al., 1997. Effects of mental stress on myocardial ischemia during daily life. JAMA 277, 1521-1526.

Jakupcak, M., et al., 2011. Hopelessness and suicidal ideation in Iraq and Afghanistan war veterans reporting subthreshold and threshold posttraumatic stress disorder. J. Nerv. Ment. Dis. 199, 272-275.

Jiang, W., et al., 1996. Mental stress-induced myocardial ischemia and cardiac events. JAMA 275, 1651-1656.
Jordan, H., et al., 2011. Mortality among survivors of the September 11, 2001 World Trade Center disaster: results from the World Trade Center Health Registry. Lancet $378,879-887$.

Joshi, R., Turnbill, F., 2009. Validity of self-reported cardiovascular disease. Intern. Med. J. 39, 5-6.

Kubzansky, L.D., et al., 2007. Prospective study of posttraumatic stress disorder symptoms and coronary heart disease in the Normative Aging Study. Arch. Gen. Psychiatry $64,109-116$

Lin, S., et al., 2010. Respiratory and cardiovascular hospitalizations after the World Trade Center disaster. Arch. Environ. Occup. Health 65, 12-20.

Marshall, R.D., et al., 2001. Comorbidity, impairment, and suicidality in subthreshold PTSD. Am. J. Psychiatry 158, 1467-1473.

Nakagawa, I., et al., 2009. Long-term effects of the Niigata-Chuetsu earthquake in Japan on acute myocardial infarction mortality: an analysis of death certificate data. Heart 95, 2009-2013.

Rozanski, A., et al., 1999. Impact of psychological factors on the pathogenesis of cardiovascular disease and implications for therapy. Circulation 99, 2192-2217.

Stalnikowicz, R., Tsafrir, A., 2002. Acute psychosocial stress and cardiovascular events. Am. J. Emerg. Med. 20, 488-491.

Stellman, J., et al., 2008. Enduring mental health morbidity and social function impair ment in World Trade Center rescue, recovery, and cleanup workers: the psychological dimension of an environmental health disaster. Environ. Health Perspect. 116 (9), 124-153.

Thurston, G., et al., 2003. Identification and characterization of World Trade Center disaster fine particulate matter air pollution at a site in lower Manhattan following September 11. Epidemiology 14, S87-S88.

Ventureyra, V., et al., 2002. The validation of the Posttraumatic Stress Disorder Checklist Scale in posttraumatic stress disorder and nonclinical subjects. Psychother Psychosom. 71, 47-53.

Weathers, F., et al., 1993. The PTSD checklist (PCL): reliability, validity, and diagnostic utility. Paper presented at: Annual Convention of the International Society for Traumatic Stress Studies San Antonio, TX 